\title{
EXTERNAL KNOWLEDGE SEARCH FOR INNOVATION: THE ROLE OF FIRMS' INNOVATION STRATEGY AND INDUSTRY CONTEXT
}

\begin{abstract}
Purpose: This paper aims to analyze the extent to which the influence of external knowledge search on innovation performance is contingent on both a firm's innovation strategy and on the industry context in which it operates.
\end{abstract}

Design/methodology/approach: The paper adopts a contingent approach that centers analysis on the influence of situational factors, either exogenous or endogenous to the organization, as determinants of the external knowledge search in promoting the firm's innovation performance. The empirical study is based on a large sample of 18,955 firms operating in 29 industries that belong to 13 European countries.

Findings: Our analysis reveals that a broad knowledge search is more effective for firms that innovate in new goods while a deeper knowledge search is more effective for firms that innovate in new services. Our results also indicate that external knowledge search varies across industries, with search depth being used more in industries in which the knowledge development process is cumulative and appropriable while the external breadth search is preferred in industries with a high level of technological opportunity.

Originality/value: Our approach implies recognizing that the knowledge search strategies may not always be effective, and that firms should align the search strategy to both internal and external factors. Analyzing the influence of these factors can help managers to better choose the type of knowledge search (e.g. intensive or extensive search) that best aligns with the firm's innovation objectives.

Keywords: External knowledge search, search breadth and depth, innovation, technological regimes.

Paper type: Research type 


\section{EXTERNAL KNOWLEDGE SEARCH FOR INNOVATION: THE ROLE OF FIRMS' INNOVATION STRATEGY AND INDUSTRY CONTEXT}

\section{Introduction}

Although internal investment in $R \& D$ continues to be the mainstay of innovative activity in firms, the capture of external ideas and resources is becoming an increasingly important part of the innovation activity. This trend to open up the innovation process is fuelled by certain environmental characteristics, such as greater market dynamism, increased worker mobility and rapid technological changes (Chesbrough, 2006). In dynamic environments firms can no longer rely solely on their internal development, favoring the participation of other external actors in the innovation process (Chesbrough, 2006; Klevorick et al., 1995; von Hippel, 1988, 2005). Previous studies highlight the advantages of combining internal R\&D investments with external resources to benefit from complementarities (e.g., Cassiman and Veugelers, 2006), and report evidence for the influence that external knowledge has on innovation performance (Chiang and Hung, 2010; Katila, 2002; Katila and Ahuja, 2002; Laursen and Salter, 2006). According to this view, knowledge search processes lead firms to develop the required skills to acquire, use and combine knowledge that, together with internal knowledge, will form the basis for innovation.

External knowledge search strategy refers to how firms organize the processes of searching for new and valuable ideas among a large and varied set of external sources of innovation (Laursen and Salter, 2006) including, among others, customers, suppliers, competitors, universities, and other public and private institutions. Previous studies have identified two dimensions: search breadth and search depth (Chiang and Hung, 2010; Katila and Ahuja, 2002; Laursen and Salter, 2006). Search breadth refers to the diversity of sources utilized, and an extensive search strategy is characterized by establishing relationships with a high number of organizations. On the other hand, search depth is related to the degree of 
intensity of the relationship with the external sources, and an intensive search strategy entails deeper relationships with the sources (Laursen and Salter, 2006).

The aim of this paper is to extend the research on the influence of the external search strategy on innovation performance by adopting a contingent perspective. In particular, we first aim to analyze to what extent the effectiveness of the external search strategy depends on two characteristics of the firm's innovative strategy, namely, the type of new products the firm introduces in the market, and the organization of these innovative activities. The second aim is to explore to what extent the knowledge search for innovation is also conditioned by elements of the industries' technological regimes such as the level of technological opportunity, level of appropriabilty and knowledge accumulation conditions.

The research is based on the idea that the configuration of the knowledge search strategy depends on a set of characteristics of the innovation strategy such as the type of innovation activities the firm engages in (e.g. innovation in goods or services), and the way they are organized (internally or externally). On the other hand, external knowledge search is shaped by external environment characteristics such as the availability of technological opportunities, the appropriability conditions of the new knowledge, or the technological base of the industry (Castellacci, 2007, Laursen and Salter, 2006; Malerba and Orsenigo, 1993).

Although previous studies have empirically analyzed the benefits and costs of intensive and extensive sourcing (Chen et al., 2011; Cruz-González et al., 2014; Laursen and Salter, 2006), less attention has been paid to the extent to which a firm's internal and external conditions favor or hinder the external search strategy. Some studies point to the need for a contingency approach that centers analysis on the influence of situational factors, either exogenous or endogenous to the organization, as determinants of the external knowledge search in promoting the firm's innovation performance (Bahemia and Squire, 2010; Huizingh, 2011; Laursen, 2012; López-Sáez et al., 2010). This approach implies recognizing that the 
knowledge search strategies may not always be effective, and that firms should align the search strategy to both internal and external factors. Analyzing the influence of these factors can help managers to better choose the type of knowledge search (e.g., intensive or extensive search) that best aligns with the firm's innovation objectives.

The rest of the paper is structured as follows. In the next section we present the theoretical framework and the hypotheses. In the second section we analyze the role of firm and industry characteristics as contextual factors that influence the external search strategy. We then describe the methodological aspects of the research and present our results. Lastly, the findings from the study are discussed and the conclusions presented.

\section{Theoretical background and hypotheses}

\subsection{Firms' innovation activities, external knowledge search and innovation performance}

Although broad and deep knowledge searches have a positive effect on innovation performance (Laursen and Salter, 2006), the effectiveness of these strategies can be conditioned by multiple contextual variables that influence the implementation of the search activities (Bahemia and Squire, 2010). Contextual variables may be internal to the organization, and related to the innovative activities of the firm, or they may be characteristics of the firm's environment, mainly the industry in which the firm operates. In this section we focus on internal factors such as the type of product (innovation in goods or services), and whether the firm innovates in products it develops itself or in products developed by other firms or institutions. In the following section we will focus on how the characteristics of the industry influence the knowledge search for innovation.

Innovation in goods versus services

Distinguishing innovation in goods from innovation in services could have implications for the effectiveness of external knowledge search activities. Open innovation studies, focused on innovation in manufacturing firms, reveal that both search breadth and depth positively 
influence innovation performance (Katila and Ahuja, 2002; Laursen and Salter, 2006; Chiang and Hung, 2010). A broad search gives firms access to a wide variety of external knowledge that enriches the firm's knowledge pool (March, 1991) and improves its chances of developing successful innovations (Leiponen and Helfat, 2010; Vega et al., 2009). By contrast, an intensive search gives firms access to a more in-depth and fine-grained knowledge for innovation (Leana and Van Buren, 1999; Chiang and Hung, 2010) that could not be acquired through a more superficial search (Hsieh and Tidd, 2012). In-depth knowledge is easier for the firm to understand and can be simply integrated into its internal innovative efforts (Laursen and Salter, 2006). Most studies on external knowledge search point out that both extensive and intensive search are suitable search strategies for innovation in goods. Based on these arguments, we propose the following hypothesis:

Hypothesis 1a. In introducing new goods, search breadth and search depth have a positive effect on innovation performance.

On the other hand, we expect that the way external knowledge is sought may be different in the case of introducing new services. The importance of person-to-person contacts, the customer orientation and the special qualification requirements within the firm are some of the peculiarities of service innovator firms (Hipp, 2008). These characteristics may influence the way in which these firms search external knowledge for innovation. Sundbo (1997) finds that external networks in service firms are relatively narrow, and that service firms are not efficient in establishing and using external networks. Tether (2005) points out that service firms collaborate more frequently with their customers and suppliers. Mention and Asikainen (2012) find that information sourcing from market players (customers, suppliers, and private consultancies) does not have a significant influence on innovation performance. The low engagement of service firms in external knowledge source 
activities may be attributable to the problem of imitation and the lack of a patent system to prevent imitation in services (Santamaría et al., 2012; Hipp and Grupp, 2005; Sundbo, 1997). Innovations in services are rapidly implemented and copied, and service firms barely have time to take advantage of their innovations. In order to avoid problems of imitability, service innovator firms tend to depend on a more intensive search. In contrast to an extensive search, an intensive relationship allows firms to develop a more profound understanding of the external source (customer, supplier, etc.) to access tacit knowledge (i.e., more in-depth and fine-grained knowledge) that is not transferable and is easier to protect than explicit knowledge (Zander and Kogut, 1995) and, therefore, more difficult to imitate. Search depth thus allows firms to overcome the problems of imitability of the external knowledge search in services. Based on these arguments, we propose that the introduction of service innovations can influence the effectiveness of external knowledge search in the following terms:

Hypothesis $1 b$. In introducing new services, the influence of external search depth on innovation performance is more effective than external search breadth.

\section{Internal and external development of innovations}

A primary variable of the firm's innovative strategy is whether the new products are developed in house or by other firms or institutions. This is related to the make/buy decision investigated by Cassiman and Veugelers (2006) in assessing the complementarity of internal R\&D and external knowledge acquisition. Vega-Jurado et al. (2008) find that both firms that develop new products internally and those that acquire them from other firms or institutions use external knowledge to search for technological complementarities. However they differ in how this complementarity is achieved. In the case of firms that develop products internally the external search is driven by acquiring knowledge related to the firm's R\&D capabilities 
(Vega-Jurado et al., 2008), capabilities lacking in firms that innovate in products developed by other firms or institutions.

To the extent that developing new products internally requires not only in-house R\&D investments, but also the technological capacities to absorb and use the external knowledge, we expect that firms that develop their products internally will be more able to make better use of the acquired knowledge. On the other hand, firms that innovate in products developed by other firms or institutions will lack the required competences to efficiently absorb and use the external knowledge. These arguments lead us to the following hypotheses:

Hypothesis 2a. External search breadth is more effective in firms that innovate in new products developed in house than in firms that innovate in new products developed externally.

Hypothesis 2b. External search depth is more effective in firms that innovate in new products developed in house than in firms that innovate in new products developed externally.

\subsection{Industry characteristics, external knowledge search, and innovation performance}

Differences in the way and the intensity in which firms search for external knowledge can also be attributable to the industry. For example, previous studies on innovation sources suggest that external knowledge search strategies are particularly beneficial for firms operating in technology-intensive industries (Hagedoorn, 1993; Katila and Ahuja, 2002; Laursen and Salter, 2006). In these industries few firms can achieve the required levels of technological development by themselves, and even the most diversified firms need to cooperate in order to respond quickly to market demands. Cohen and Levinthal (1990) 
suggest that, in general, industry characteristics such as the availability of technological opportunities and environmental turbulence affect knowledge search activities.

Several authors (e.g., Malerba, 2002; Malerba and Orsenigo, 1993, 1997; Castellacci, 2007) have proposed a typology of sectoral patterns of innovation with which to analyze the effect of specific industry characteristics on the external knowledge search strategy. Each sector has a series of technological features that shapes its firms' technological environment and conditions their innovation activities. These technological characteristics, which make up the technological regime of the industry (Nelson and Winter, 1982; Winter, 1984), influence the direction and intensity of the innovative processes in the firm (Castellacci, 2007). Three dimensions of technological regimes have been identified: level of technological opportunity, appropriability, and accumulation conditions (Malerba and Orsenigo, 1993). Below we analyze the possible effect of these dimensions on the use of extensive and intensive searches in developing new product innovations.

\section{Level of technological opportunity and external knowledge search}

The level of technological opportunity is defined as the likelihood of achieving one or more innovations given a specific amount of R\&D expenditure (Malerba and Orsenigo, 1993). In environments with high technological opportunities firms tend to search externally in order to “keep pace with progress" (Malerba and Orsenigo, 1993). In some technologically dynamic sectors, such as biotechnology, external search activities remain a distinctive feature (Powell et al., 1996).

Levinthal and March (1993) and Nelson and Winter (1982) have suggested that search strategies are strongly influenced by the wealth of opportunities available in the environment and by the search activities carried out by other firms. In industries with high levels of technological opportunities and where other firms make considerable investments in search 
activities, a firm will need to search more broadly and deeply in order to gain access to important sources of knowledge (Laursen and Salter, 2006). However, in industries where technological opportunities are low, and search investment by other firms is modest, a firm may have fewer incentives to learn from external sources due to the difficulty in finding relevant external sources to attain better innovation results (Klevorick et al., 1995). Therefore, it is expected that the level of opportunity will have a positive influence on the use of external knowledge sourcing activities.

Hypothesis 3a. The higher the technological opportunity in the sector, the higher the external knowledge search.

The level of opportunity could also influence the type of external search in the industry. When there are plenty of opportunities to acquire valuable knowledge and ideas, firms are more likely to engage in breadth search activities that give them access to a wide range of external knowledge coming from different sources. The availability of relevant external knowledge offsets the increasing complexity of managing the large number of relationships needed to maintain access to these sources (Leiponen and Helfat, 2010). On the other hand, in industries characterized by a low level of opportunities and where the likelihood of obtaining relevant external knowledge is low, firms will focus on search activities only in those specific sources that are able to provide valuable knowledge for innovation. In this context, firms need to develop deeper relationships to absorb valuable knowledge that will otherwise not be available. These arguments lead us to propose the following hypothesis. 
Hypothesis 3b. The positive influence of technological opportunity is higher in extensive knowledge search than in intensive knowledge search.

\section{Appropriability conditions and external knowledge search}

Appropriability conditions refer to the possibilities of obtaining rents by protecting innovation against imitation (Malerba and Orsenigo, 1993). Firms protect their innovations through a variety of mechanisms, which may be formal such as patents, or informal as with trade secrets, know-how, or tacit knowledge. The level of appropriability and the effectiveness of the mechanisms of appropriation differ greatly from industry to industry (Levin et al., 1987; Malerba and Orsenigo, 1997). Some industries are highly protective (e.g., chemical and pharmaceutical), while in other industries no appropriation mechanisms are particularly effective (e.g., food products, metal-working sectors) (Levin et al., 1987).

There is little research into the influence of appropriability conditions on external knowledge search strategies. Previous studies have found that in industries with high levels of appropriability firms have less incentive to open up their innovation process, given that excessive protection limits the possibility of knowledge exchange between firms (Laursen and Salter, 2014). The search for external knowledge is therefore curbed by the difficulty of accessing knowledge relevant to the firm, and external knowledge search becomes a less profitable strategy. Therefore, it is expected that the level of appropriability will deter search activities for external knowledge.

Hypothesis 4a. Appropriability conditions hinder the use of external knowledge search.

The ability to overcome the difficulties of obtaining valuable external knowledge in protectionist environments differs between broad and deep searches. By increasing the 
number of external sources involved in the search activities firms may increase the chance that at least one of them will provide relevant external knowledge in an environment of high appropriability (Leiponen and Helfat, 2010). However, this chance will be higher when the relationship with the external sources is deeper. A deep search implies that firms sustain strong and frequent contacts over time with the external sources in order to build a deep shared understanding and a common way of working together (Laursen and Salter, 2006). This mutual understanding increases the trust between the firm and the external source, thereby lowering the barriers to obtaining valuable knowledge. These arguments suggest that in more protectionist environments firms will tend to develop intensive rather than extensive search strategies, leading us to the following hypothesis:

Hypothesis 4b. In industries with high level of appropriability conditions, firms prefer a deep search to a broad search.

\section{Knowledge accumulation conditions and external knowledge search}

Accumulation conditions are based on the idea that innovations and current innovative activities provide the foundations for future innovations, and firms that are currently more innovative will be more likely to innovate in the future than those that are not (Malerba and Orsenigo, 1993). Accumulation conditions differ across sectors, thus affecting the intensity and direction of technological change in each sector. In industries where knowledge is cumulative —or in Schumpeterian terms, contexts of "creative accumulation"- technological advantages tend to be stable and feed back into themselves, creating an environment characterized by increasing returns in knowledge creation (Malerba, 2002). Innovations in these environments do not imply a breakdown of pre-existing technological bases in the industry. 
In contrast, less accumulative knowledge environments correspond to the Schumpeterian model of "creative destruction" (Malerba, 2002). Frequent radical innovations lead to technological discontinuities and paradigm shifts, causing previously accumulated knowledge to quickly become obsolete (Henderson and Clark, 1990) and also a higher degree of discontinuity in the sources of innovation (Christensen, 1997; Utterback and Abernathy, 1975).

The knowledge accumulation conditions influence the innovative activities of the industry and therefore the suitability of conducting broad or deep knowledge searches. In cumulative knowledge environments, relevant knowledge for the firm needs to be related to its current knowledge base. Firms have fewer incentives to search in new distal knowledge sources than to deepen the search in sources whose knowledge bases are close to them. Building deep relationships with current external sources has some advantages in this context. First, if the new knowledge is related to the firm's knowledge base, intensive searches make it easy to identify valuable knowledge elements and increase the probability of combining the new knowledge in different and significant ways (Ahuja and Katila, 2001). Second, deep searching enables the organization to obtain valuable knowledge that could not be acquired through a more superficial search (Hsieh and Tidd, 2012). In addition, the costs of an intensive search are lower, since searching in sources with related knowledge bases makes the search more reliable, and reduces the likelihood of errors and false starts (Levinthal and March, 1981). Based on these arguments, we propose that firms in industries with a high level of knowledge accumulation will have incentives to search selectively and learn from external sources that provide knowledge close to their own knowledge base. This argument leads us to the following hypothesis: 
Hypothesis 5a. The higher the accumulation conditions, the higher the intensive knowledge search.

On the other hand, an extensive search is less preferable in contexts characterized by a high cumulative knowledge. Broad searching implies looking for knowledge from a wide number of sources, some of whose knowledge bases have only a weak connection with the firm's technological competences. In this context firms are not interested in searching in sources that are not in line with the knowledge accumulation path (i.e., sources with knowledge bases unrelated to the firm's technological competence). This "non-related" knowledge is less valuable to the firm, since innovations in knowledge cumulative industries are based more on exploiting existing knowledge than on exploring new distal knowledge. Additionally, search costs may rise steeply due to the increased complexity of managing a changing set of knowledge sources and relationships to maintain access to external knowledge (Leiponen and Helfat, 2010). We therefore expect that in highly knowledge accumulative industries, firms will have fewer incentives to engage in a broad search.

Hypothesis 5b. The higher the accumulation conditions in the sector, the lower the extensive knowledge search.

\section{Methods}

\subsection{Data and sample}

We use data from the Community Innovation Survey 2006 (CIS-2006), a European database that collects information on the innovation activities of European firms with at least 10 employees. The CIS-2006 covers the period 2004-2006, and includes information on the characteristics of innovative firms, the innovation activities they carry out, and their 
innovation results. The survey also contains information on a large number of factors that may favor or hinder innovation activities, including those related to the use of external knowledge sources for the development of new product innovations. The data is collected by the European Union (EU) member states, mainly through a postal survey (in some cases with a combination of postal and electronic surveys) addressed to the heads of R\&D or Innovation Management departments. Eurostat's quality control rules are applied during data processing; these controls include re-contact with the firms, imputation, and non-response analysis to eliminate unit and/or item non-response (Eurostat, 2006).

Although the survey comprises information from all the 27 countries members of the EU in 2006 and Norway, the confidentiality of the data and agreements between Eurostat and EU members prevented us from accessing responses from all member states. Therefore, in this paper, we only analyze information referring to 13 countries: Bulgaria (BG), Cyprus (CY), Czech Republic (CZ), Estonia (EE), Greece (EL), Spain (ES), Hungary (HU), Lithuania (LT), Norway (NO), Portugal (PT), Romania (RO), Slovenia (SI) and Slovakia (SK). The target population of the CIS-2006 is European firms carrying out market activities (NACE activities C to K) (Eurostat, 2006). The CIS-2006 classifies the firms into 29 industries (at 2-digit NACE), although the coverage of the sample for each industry varies depending on whether the industries are classified as either "core" or "non-core". Of the 93,192 firms contained in the initial sample, we use information on 20,539 firms that introduced new or significantly improved goods or services during the period 2004-2006 (i.e., innovator firms). Table 1 shows the distribution of firms by country and industry. In the statistical analyses a further 1,584 firms were also excluded because they did not report information on either the independent variables $(1,522)$ or the dependent variable $(62)$. The final sample was therefore made up of 18,955 firms. 
[Insert table 1 here]

\subsection{Measures}

The following measures were used in the statistical analyses.

Innovation performance. Several approaches have been used to measure innovation performance (see Hagedoorn and Cloodt, 2003). While some studies focus on innovation inputs (e.g., R\&D expenditures), others explore the outcome of innovation efforts, such as patents, new processes, services and/or products. Consistent with previous CIS work (e.g., Köhler, Sofka, and Grimpe, 2012; Leiponen and Helfat, 2010; Sofka and Grimpe, 2010), we follow this latter approach. We define the variable innovation performance for the market (INMAR) as the dependent variable to operationalize firm innovation performance. INMAR is measured as the percentage of the firm's sales in 2006 due to innovations in new-to-themarket products (goods and services) introduced by the firm during the period 2004-2006.

External knowledge search. The breadth and depth dimensions of the external knowledge search strategy were measured following the approach proposed by Laursen and Salter (2006). The search breadth dimension was measured as the number of external knowledge sources relevant to the development of innovative activities that the firm used during the years 2004-2006. Nine different external sources were used: four sources classified as "market sources" by the CIS-2006 (suppliers of equipment, materials, components, or software; clients or customers; competitors or other enterprises in the firm's sector; and consultants, commercial labs, or private R\&D institutes); two as "institutional sources" (universities or other higher education institutions; and government or public research institutes) and three as "other sources" (conferences, trade fairs, exhibitions; scientific journals and trade/technical publications; and professional and industry associations). The search breadth variable (SBREADTH) was operationalized by adding the 
number of external sources used by the firm. Thus, SBREADTH ranged from ' 0 ' to '9', taking the value ' 0 ' when the firm did not use any source, and ' 9 ' when it used all external sources for which information was available in CIS-2006.

The search depth dimension, which measures the degree of importance to innovation activities of the external knowledge sources the firm uses, was operationalized using the same nine external sources as in the variable SBREADTH. In this case, the relevant information was the degree of importance of each of the nine external sources that the CIS-2006 classified as "high", "medium" and "low". The variable SDEPTH was calculated by adding the number of sources with a high degree of use, obtaining a new variable ranging from ' 0 ' to '9', where the value ' 0 ' indicated that the firm did not use any source intensively, and ' 9 ' reflected intensive use of all external sources.

Internal context: Firms' innovation activities. We classify the firms into three groups according to whether they introduce new goods, new services, or both. In the sample, 10,180 firms introduced new or significantly improved goods; 4,167 launched new or significantly improved services; and 4,608 firms introduced both new or significantly improved goods and services. Second, we classify the firms according to whether the products the firm introduced were developed in house, or by other firms or institutions (i.e., extramural). In the sample, 14,266 firms introduced new or significantly improved products that were mainly developed in house (we call firms in this group "developers"); while 1,505 firms introduced new products that were mainly developed externally ("adopters"). The remaining 3,184 firms in which the product innovation was primarily developed in collaboration with other firms or institutions (a mix of "adopters" and "developers") were excluded from the analysis.

External context: Characteristics of the technological regime of the industry. We followed Castellacci (2007) to measure the characteristics of the sectoral technological regime. The variable level of technological opportunity (IOPPOR) measured the percentage 
of firms in the industry that invested in internal R\&D during the period 2004-2006. The variable appropriability conditions (IAPPROP) measured the percentage of firms in the industry that protected their innovations through patents, registered industrial designs, or trademarks during the period 2004-2006. Finally, the variable knowledge accumulation conditions (IACCUM) measured the percentage of firms in the sector that continuously invested in R\&D every year (annually) during the period 2004-2006. To avoid the possible oversampled representation of innovative firms, all the shares referred to the population of firms.

Control variables. In the regression equations we include a set of control variables with a possible influence on the firm's innovation performance. Specifically, we control for the level of internal R\&D investment ( $R \& D$ intensity, RDINT), measured by the ratio of total R\&D expenditures to sales in 2006; and the size of the firm (SIZE), measured using a categorical variable codified as ' 1 ' for small firms (fewer than 50 employees), ' 2 ' for medium-sized firms (50 to 249 employees) and '3' for large firms (250 or more employees). Other control variables used in the regression equations were a set of 28 dummy variables for the industry (with industry 1 Mining as a reference category; see the description of the industries in Table 1) and also 12 dummies for the country, to account for the different propensities to innovate across industries and countries, respectively. Finally, in line with previous studies (e.g., Laursen and Salter, 2006), we also control for collaboration arrangements with customers (USER) and in any innovation activity (COLLAB); as well as for the size of the geographic markets where the firm sells its goods or services (local or regional, national, other European Union countries, or all other countries). The anonymization of the Eurostat data restricts access to other firm characteristics, thus precluding the use of alternative control variables. 


\subsection{Analytical procedure}

To test our hypotheses, we first assessed the influence of external knowledge search strategy (SBREADTH and SDEPTH) on the innovation performance measure INMAR outlined above. A censored regression (i.e., Tobit model) was estimated to take into account that the dependent variable INMAR, measured as a percentage, is censored. To align the specification of the model with previous studies (e.g., Laursen and Salter, 1996), in the regression equation we include the control variables described in the previous subsection, including both the industry and country dummy variables. However we do not include the quadratic terms for the breadth and depth dimensions. The variables SBREADTH (and SDEPTH) and their squares were very highly correlated (0.97 and 0.90 , respectively), so they were indistinguishable and cannot be used simultaneously as covariates in the regression equation. ${ }^{\text {ii }}$ Finally, robust standard errors were used to protect inferences from possible deviation from non-normality. All the innovative firms in the sample $(n=18,955)$ were fed into this analysis.

Second, a multiple-group SEM analysis was proposed to test for possible differences in the effectiveness of the external knowledge search strategy among innovative firms developing different innovation activities (hypotheses H1a,b and H2a,b). Here, we classify the firms into groups according to the type of product innovations they introduced (goods, services, or both), and to where the new products were developed (i.e., in the firm itself or in other firms or institutions). In the multiple-group analyses the regression coefficients (and the error terms) were regarded as group-specific parameters. Therefore, they were freely estimated for each group to capture the influence of SBREADTH and SDEPTH on INMAR across groups of firms with different innovation activities. As in the previous analysis, a Tobit model was estimated for each group, using standard errors robust to non-normality.

Finally, to assess the effect of the industry characteristics on the knowledge search strategies and innovation performance (hypotheses $\mathrm{H} 3 \mathrm{a}, \mathrm{b}$ to $\mathrm{H} 5 \mathrm{a}, \mathrm{b}$ ), the breadth and depth 
dimensions of the external knowledge search strategy were regressed on the variables characterizing the technological regime of the industry (IAPPROP, IOPPOR, and IACCUM). Since the technological regime characteristics may directly impact innovation performance without influencing its search strategies, direct effects of IAPPROP, IOPPOR, and IACCUM on INMAR were also included in the model. All the models were estimated using SEM software Mplus (Muthén and Muthén, 1998-2012). As in the previous analyses, robust standard errors were used to protect inferences from possible deviation from non-normality.

\subsection{Descriptive analysis}

Table 2 shows the mean values of the dependent and dependent variables by industry. In terms of extensive external knowledge search (SBREADTH), the firms in the sample use an average of 5.58 external information sources, with significant differences among industrial sectors. For example, the Petroleum and chemicals (6.45) and Electricity gas, steam and hot water supply (6.22) sectors have the greatest openness to external knowledge sources. In contrast, less technologically intensive sectors such as Hotels and restaurants (2.73) or Real estate activities (3.68) use a small number of external knowledge sources. In the intensive search strategy (SDEPTH), the average number of sources used is 1.27. The Post and communication (1.54) and Wholesale trade (1.44) sectors use a larger number of external knowledge sources intensively. Other sectors such as Renting of machinery and equipment (0.66), Hotels and restaurants (0.77), Construction (0.79) and Real estate activities (0.79) use, on average, less than one external source of knowledge intensively.

Table 2 also shows that the sectors with the highest rates of product innovation, such as Computer and related activities (24.72 per cent of the total sales in 2006), $R \& D$ and other business activities (19.5), or Electrical and optical equipment, medical equipment, radio, TV (18.16) also present higher average scores in the variables characterizing the technological 
regime of the industry. At the other extreme, industries with low levels of product innovation such as Hotels and restaurants (4.65) or Land, air and water transport (9.68) also obtain below average values in the technological regime variables.

[Insert table 2 here]

\section{Results}

\subsection{Influence of knowledge search strategies on innovation performance}

Panel A in Table 3 shows the results of the Tobit model for the whole sample of innovative firms. The results indicate that both intensive and extensive knowledge search strategies have a positive and significant effect on innovation performance. In particular, the results for the SBREADTH indicate that the use of an additional external knowledge source increases the percentage of firms' sales in new-to-the-market products and services by an average of 1.095 percentage points $($ s.e. $=0.152)$. The same results are obtained for the variable SDEPTH, in which the intensive use of an additional external knowledge source also increases the percentage of sales in new products by an average of 1.095 points $(\mathrm{s} . \mathrm{e} .=0.255)$.

4.2 Influence of the firm's innovation activities on the effectiveness of external knowledge search strategy

Panels B and $\mathrm{C}$ in Table 3 show the influence of SBREADTH and SDEPTH on INMAR when innovative firms are classified in groups with different innovation activities. These analyses correspond to the multiple-group analyses. Overall, the results suggest that the influence of external search strategies on innovation performance varies across groups. Regarding the type of product innovation introduced, the extensive external knowledge search strategy has a positive influence on innovation performance for firms introducing new or significantly improved goods $(1.276$; s.e. $=0.204)$, but the influence is not significant for 
either service innovator firms $(0.584$; s.e. $=0.395)$, or firms that innovate in both goods and services $(0.502$; s.e. $=0.280)$. In the case of intensive external search our results indicate that SDEPTH has a significant influence for firms that only innovate in new services (2.659; s.e. $=0.688)$, but there is no significant influence for firms that innovate in goods $(0.618$; s.e. $=0.380)$ or in both goods and services $(0.680$; s.e. $=0.382)$. These results support hypotheses H1a (in the case of breadth search) and H1b.

Regarding where the product innovations are developed — in house or extramural—we find that for both "developers" and "adopters" the influence of external knowledge search (SBREADTH and SDEPTH) on innovation performance is statistically significant. However, the strength of the influence of the SBREADTH and SDEPTH on INMAR is higher in the group of "adopters" (1.569 [s.e.=0.647] and 3.065[s.e.=1.224], respectively) than in the case of "developers" $(0.174$ [s.e. $=0.647$ ] and 0.772 [s.e.=0.302]), a result that leads us to reject hypotheses $\mathrm{H} 2 \mathrm{a}$ and $\mathrm{H} 2 \mathrm{~b}$.

[Insert table 3 here]

\subsection{Effect of industry characteristics on innovation performance and effectiveness of external} knowledge search

Table 4 shows the effect of the characteristics of the technological regime of the industry on the external knowledge search strategy (SBREADTH and SDEPTH), and on innovation performance. The table shows that the level of opportunity of the industry (IOPPORT) has a significant positive influence on SBREADTH $(0.034$; s.e. $=0.003)$, but the influence on SDEPTH is not significant. These results confirm hypothesis $\mathrm{H} 3 \mathrm{a}$ that the technological opportunity of the industry has a positive influence on external search, but only in the case of the broad search dimension. We also find that the (positive) influence of the IOPPORT is 
higher in the case of SBREADTH than for the SDEPTH dimension, a result that is in accordance with hypothesis $\mathrm{H} 3 \mathrm{~b}$.

The influence of level of appropriability is seen in Table 4, which shows the significant positive influence of IAPPROP on the use of intensive search $(0.010$; s.e. $=0.005)$, which is also positive in the case of SBREADTH, although not significant. H4a, which proposed a negative influence of the level appropriability of the industry on both the breadth and depth dimensions of the external sourcing, is therefore rejected. However, IAPPROP has a higher influence on SDEPTH than on SBREADTH, thus lending support to hypothesis H4b.

Finally, the influence of the level of accumulation of the industry is seen in Table 4, which shows the positive and statistically significant $(0.006$; s.e. $=0.002)$ effect of IACCUM on SDEPTH, a result that confirms hypothesis H5a. We also find a negative influence of IAPPROP on SBREADTH, as proposed in hypothesis $\mathrm{H} 5 \mathrm{~b}$, although the regression coefficient is not statistically significant. We therefore find no evidence for a significant negative influence of IAPPROP on SBREADTH; hypothesis H5b is thus rejected.

The bottom part of Table 4 shows the (direct) effect of the technological regime characteristics on innovation performance. We find a positive influence of IOPPORT $(0.216$; s.e. $=0.056)$ and IACCUM $(0.228$; s.e. $=0.061)$ on INMAR, while the influence of IAPPROP is negative $(-0.271$; s.e. $=0.088)$. Overall, these results suggest that the technological regime of the industry matters in explaining across-industry variations in the use of knowledge search strategy and also the firm's innovation performance.

[Insert table 4 here]

\section{Discussion}


As far as the relationship between external knowledge search strategy and innovation performance relationship is concerned, the analysis reports a positive (and similar in size) influence on innovation performance of both the breadth and the depth dimensions of the search strategy. These results are broadly in line with previous studies showing that investment in the search for external sources favors innovation performance (Chiang and Hung, 2010; Garriga et al., 2013; Katila, 2002; Katila and Ahuja, 2002; Laursen and Salter, 2006). These studies, however, provide conflicting evidence on the magnitude of the effects. For instance, Laursen and Salter (2006) found that the influence of search breadth was relatively higher than search depth, while Katila and Ahuja (2002) reported the opposite. Conversely, Chiang and Hung (2010) found that breadth search has a significant positive effect on innovation performance, while the effect of intensive search is not significant. Differences in results have been attributed to methodological issues (i.e., estimation methods), measures of innovation performance (radical or incremental) and search strategy, and also to the size and the scope (single or multiple industries) of the sample (Garriga et al., 2013). Our study extends the empirical base of the external knowledge search and innovation performance relationship, providing additional evidence of the positive association across different industries and countries.

In relation to hypotheses $\mathrm{H} 1 \mathrm{a}$ and $\mathrm{H} 1 \mathrm{~b}$ (the influence of external knowledge search is different in firms that innovate in new goods from those innovating in new services), we found that only the search breadth strategy positively affects innovation performance in the case of firms that innovate in new goods. In the case of firms that innovate in new services, we found a higher significant effect of search depth on innovation performance than search breadth, which is not significant. Our findings add to the argument made in studies analyzing manufacturing firms that a broad search strategy allows firms to access a wide range of knowledge coming from diverse external sources, which in turn increases the likelihood of 
finding valuable knowledge with which to develop their innovation activities (Laursen and Salter, 2006; Leiponen and Helfat, 2010). Moreover, we also find that search depth is more effective than search breadth in introducing new services. Hence, hypothesis H1b is supported. Problems of imitation or the difficulty of protecting service innovations mean firms prefer to engage in deeper relationships with a limited number of external sources and focus on those sources that may have a more direct effect on the development of innovations. Overall, our results suggest that external knowledge search decisions are aligned with key decisions in the firm's innovation strategy such as the type of innovation the firm develops (good or service).

Concerning the development of new products in house or externally (hypotheses $\mathrm{H} 2 \mathrm{a}$ and $\mathrm{H} 2 \mathrm{~b}$ ), the significant positive influence of search breadth and depth on innovation performance suggest that both "developers" and "adopters" use external sources of knowledge as a way to improve firm's innovation performance. In relation to internal "developers", this result highlights the idea underlying the open innovation approach that a firm's innovation process is based on internal development combined with external knowledge search (Chesbrough, 2006; Cassiman and Veugelers, 2006). In the case of firms in which the new products are developed externally, the external knowledge search is a way of accessing new knowledge without compromising more internal resources. This approach closely resembles the "external model" of innovation in which firms pursued "fully-fledged" innovations that are developed externally (Tether and Tajar, 2008, p. 1081).

Perhaps most notable is the result that the magnitude of the effects of both search modes (breadth and depth) is higher for "adopters" than for "developers", a result that leads us to reject hypotheses $\mathrm{H} 2 \mathrm{a}$ and $\mathrm{H} 2 \mathrm{~b}$. To facilitate a more accurate understanding of these results, it might be interesting to focus not only on the scope of the knowledge search and how firms search (the breadth and depth of knowledge sources), but also on what types of 
external sources are used, and what unique contribution they make to innovation performance. For instance, in an analysis of the influence of consultants and other private research organizations as external knowledge sources for innovation, Tether and Tajar (2008) found that these specialist knowledge providers have more abilities to develop ready-tomarket innovations than other sources such as universities, and, in turn, a higher influence on innovation performance. The analysis of the influence of specific external knowledge sources on innovation performance would provide interesting insights about their relative importance in specific contexts, and also how external sources complement or substitute one another.

The paper also adopts a contingent approach to analyze the effect of the characteristics of the industry's technological regime on the configuration of external knowledge search strategy. Our results give support to hypotheses H3a (in the case of depth search) and $\mathrm{H} 3 \mathrm{~b}$, which poses that industries with a high level of technological opportunities favor using a broad range of external knowledge sources. In contexts where there are plenty of possibilities to access valuable external knowledge, firms have greater incentives to perform an extensive search. The cost of performing search activities with a large number of external sources are offset by the benefits derived from accessing valuable knowledge from the industry. With regard to the appropriability conditions, we find evidence that high levels of knowledge appropriability encourage a greater use of intensive relationships than a broader use of the external sources. In environments with higher levels of knowledge protectionism, firms have fewer incentives to search for external knowledge because the likelihood of accessing valuable external knowledge is lower (Laursen and Salter, 2014). An intensive search strategy appears to be the best strategy to access this external knowledge. Establishing deeper relationships with a limited number of external sources increases a firm's ability to access relevant knowledge, since deep relationships with external sources increase mutual understanding and trust that, in turn, lower the barriers to relevant knowledge. Finally, we 
found evidence that the level of knowledge accumulation in the industry favors the use of an intensive search strategy. In contexts of "creative accumulation", characterized by continued investments in $R \& D$, firms typically enjoy stable technological advantages and increasing returns to knowledge creation (Malerba, 2002). Such contexts encourage firms to open up their innovation process to increase their possibilities of accessing relevant external knowledge for developing innovations. Nevertheless, knowledge accumulation requires a high and sustained effort to develop new valuable knowledge that can only be obtained when firms engage in ongoing and long-lasting relationships.

\section{Conclusion}

This paper analyzes the extent to which a firm's external search strategy is influenced by its innovation decisions and the characteristics of the sector in which it operates. Our analysis of a large database of innovator firms operating in manufacturing and service industries from 13 European countries reveals that firms conducting broader and deeper searches for knowledge and ideas among external agents attain better innovation results. We also found that the knowledge search strategy-innovation performance relationship is conditioned by the innovation activities firms adopt and by the characteristics of the technological regimen of the industry where the firm operates.

\section{Managerial implications}

Our results have also implications for management practice. The findings derived from this research may assist managers to decide the appropriate external knowledge search strategy in different contexts. Managers need to be aware that knowledge search strategies may not always be effective (i.e., result in higher innovation performance) and that their influence is contingent on both the pursued innovation strategy and the industry context. Therefore, they should select the type of external knowledge search (intensive or extensive 
search) that best aligns with the firm's innovation objectives. For example, our results suggest that broad knowledge search strategies may be more effective for manufacturing firms while deeper knowledge searches may be more effective for firms that innovate in new services. Similarly, the breadth search strategy may be preferred in industries with a high level of technological opportunity while depth search may report better results in industries in which the knowledge process is cumulative and appropriable.

\section{Limitations and future research}

A number of limitations need to be acknowledged when interpreting the results presented in the paper. Specifically, the analysis is based on cross-sectional data, making it difficult to identify any causal relationships. The CIS database is an important source of information for research into innovation in the European Union area. However, some characteristics of the database impose a number of restrictions on our research. The CIS data have only recently been released by Eurostat in the form of anonymized data, which prevents firms being identified. The anonymization process limits the use of the CIS database as a panel data, since it is impossible to trace firms' responses over time. In addition, despite the advantages of the size and representativeness of the our data, future research should explore this relationship by drawing on different data sources, measures, and research designs in order to assess the generality of our results. Such future research will shed further light on the conclusions reached in this article concerning the importance of sourcing activities for innovation performance. Specifically, in our analysis we were able to capture only a relatively small set of European countries, some of them similar in terms of the characteristics of their national institutional context. For reasons of confidentiality, our analysis does not cover leading countries in innovation at the European level such as Finland, Denmark, Germany, France and Belgium, which could provide additional evidence of the influence of the contextual variables on the external knowledge search. 
Finally, we have analyzed the influence of the characteristics of the industry's technological regime on the external knowledge search in isolation. However, it is reasonable to assume the existence of interactive effects. For instance, Malerba and Orsenigo (1993) point out that a high level of accumulation in the industry may be present if appropriability conditions are low and the relevant knowledge base for innovation is widely disseminated across the firms in the industry. Future research could usefully analyze the extent to which different industry characteristics interact and influence the modes of knowledge search. In this case scenarios representing different levels of technological regime variables could be defined in order to explore in which scenario the choice of external search strategy is more appropriate for firms to obtain innovation performance.

\section{References}

Ahuja, G. and Katila, R. (2001), "Technological acquisitions and the innovation performance of acquiring firms: A longitudinal study", Strategic Management Journal, Vol. 22 No.3, pp. 197-220.

Bahemia, H. and Squire, B. (2010), “A contingent perspective of open innovation in new product development projects", International Journal of Innovation Management, Vol. 14 No. 4, pp. 603-627.

Bayona, C., García, M. and Huerta, E. (2001), "Firms' motivations for cooperative R\&D: An empirical analysis of Spanish firms", Research Policy, Vol. 30 No. 8, pp. 1289-1307.

Cassiman, B. and Veugelers, R. (2006), "In search of complementarity in innovation strategy: Internal R\&D and external knowledge acquisition”, Management Science, Vol. 52 No. 1, pp. 68-82.

Castellacci, F. (2007), "Technological regimes and sectoral differences in productivity growth", Industrial and Corporate Change, Vol. 16 No. 6, pp. 1105-1145.

Chen, J., Chen, Y. and Vanhaverbeke, W. (2011), "The influence of scope, depth, and orientation of external technology sources on the innovative performance of Chinese firms", Technovation, Vol. 31, pp. 362-373.

Chesbrough, H. (2006), "Open innovation: A new paradigm for understanding industrial innovation", in Chesbrough H, Vanhaverbeke W, West J. (eds), Open Innovation: Researching a New Paradigm, Oxford University Press, chapter 1.

Chiang, Y.H. and Hung, K.P. (2010), "Exploring open search strategies and perceived innovation performance from the perspective of inter-organizational knowledge flows", $R \& D$ Management, Vol. 40 No. 3, pp. 292-299.

Christensen, C. (1997), The innovator's dilemma: When new technologies cause great firms to fail. Harvard Business School Press: Cambridge, MA.

Cohen, W.M. and Levinthal, D.A. (1990), "Absorptive capacity: A new perspective on learning and innovation", Administrative Science Quarterly, Vol. 35 No. 1, pp. 128-152. 
Cruz-González, J., López-Sáez, P., Navas-López, J.E. and Delgado-Verde, M. (2014), "Directions of external knowledge search: Investigating their different impact on firm performance in high-technology industries", Journal of Knowledge Management, Vol. 18 No. 5, pp. 847-866.

Eurostat (2006), The Community Innovation Survey 2006. Methodological recommendations, april 2006.

Garriga, H., von Krogh, G. and Spaeth, S. (2013), "How constraints and knowledge impact open innovation”, Strategic Management Journal, Vol. 34 No. 9, pp.1134-1144.

Hagedoorn, J. (1993), "Understanding the rationale of strategic technology partnering: interorganizational modes of cooperation and sectoral differences", Strategic Management Journal, Vol. 14 No. 5, pp. 371-385.

Hagedoorn, J. and Cloodt, M. (2003), "Measuring innovative performance: Is there an advantage in using multiple indicators?", Research Policy, Vol. 32 No. 8, pp.1365-1379.

Henderson, R.M. and Clark, K.B. (1990), "Architectural innovation: The reconfiguration of existing product technologies and the failure of established firms", Administrative Science Quarterly, Vol. 35 No. 1, pp. 9-30.

Hipp, C. (2008), "Service peculiarities and the specific role of technology in service innovation management", International Journal of Services Technology and Management, Vol. 9 No. 2, pp. 154-173.

Hipp, C. and Grupp, H. (2005), "Innovation in the service sector: The demand for servicespecific innovation measurement concepts and typologies", Research Policy, Vol. 34 No. 4, pp. 517-535.

Hsieh, K.N. and Tidd, J. (2012), "Open versus closed new service development: The influences of project novelty", Technovation, Vol. 32 No. 11, pp. 600-608.

Huizingh, E. (2011), "Open innovation: State of the art and future perspectives", Technovation, Vol. 31 No. 1, pp. 2-9.

Katila, R. (2002), "New product search over time: Past ideas in their prime?" Academy of Management Journal, Vol. 45 No. 5, pp. 995-1010.

Katila, R. and Ahuja, G. (2002), "Something old, something new: A longitudinal study of search behavior and new product introduction", Academy of Management Journal, Vol. 45 No. 6, pp. 1183-1194.

Klevorick, A.K., Levin, R., Nelson, R.R. and Winter S.G. (1995), "On the sources and significance of interindustry differences in technological opportunities", Research Policy, Vol. 24 No. 2, pp. 185-205.

Köhler, C., Sofka, W. and Grimpe, C. (2012), "Selective search, sectoral patterns, and the impact on product innovation performance", Research Policy, Vol. 41 No. 8, pp. 13441356

Laursen, K. (2012), “Keep searching and you'll find: What do we know about variety creation through firms' search activities for innovation?", Industrial and Corporate Change, Vol. 21 (5), pp. 1181-1220.

Laursen, K. and Salter, A. (2006), "Open for innovation: The role of openness in explaining innovation performance among U.K. manufacturing firms", Strategic Management Journal, Vol. 27 No. 2, pp. 131-150.

Laursen, K. and Salter, A. (2014), "The paradox of openness: Appropriability, external search and collaboration", Research Policy, Vol. 43 No. 5, pp. 867-878.

Leana, C. R. and Van Buren, H. J. (1999), "Organizational social capital and employment practices", Academy of Management Review, Vol. 24 No. 3, pp. 538-555.

Leiponen, A. and Helfat, C.E. (2010), "Innovation objectives, knowledge sources, and the benefits of breadth", Strategic Management Journal, Vol. 31 No. 2, pp. 224-236. 
Levin, R.C., Klevorick, A.K., Nelson, R.R. and Winter, S.G. (1987), "Appropriating the returns from industrial research and development", Brookings Papers on Economic Activity, Vol. 3, pp. 783-831.

Levinthal, D. and March, J.G. (1981), “A model of adaptive organizational search”, Journal of Economic Behavior \& Organization, Vol. 2 No. 4, pp. 307-333.

Levinthal, D.A. and March, J.G. (1993), "The myopia of learning", Strategic Management Journal, Vol. 14 No. S2, pp.1495-112.

López-Sáez, P., Emilio Navas-López, J., Martín-de-Castro, G., and Cruz-González, J. (2010), "External knowledge acquisition processes in knowledge-intensive clusters", Journal of Knowledge Management, Vol. 14 No. 5, pp. 690-707.

Malerba, F. (2002), "Sectoral systems of innovation and production", Research Policy, Vol. 31 No. 2, pp. 247-264.

Malerba, F. and Orsenigo, L. (1993), "Technological regimes and firm behaviour", Industrial and Corporate Change, Vol. 2 No. 1, pp. 45-72.

Malerba, F. and Orsenigo, L. (1997), "Technological regimes and sectoral patterns of innovative activities", Industrial and Corporate Change, Vol. 6 No. 1, pp. 83-117.

March, J.G. (1991), "Exploration and exploitation in organizational learning", Organization Science, Vol. 2 No. 1, pp. 71-87.

Mention, A. and Asikainen, A. (2012), "Innovation \& productivity: Investigating effects of openness in services", International Journal of Innovation Management, Vol. 16 No. 3, pp. 1240004-1-1240004-27.

Muthén, L.K. and Muthén B. O. (1998-2012), Mplus User's Guide. Seventh Edition. Los Angeles, CA: Muthén and Muthén.

Nelson, R.R. and Winter, S.G. (1982), "The schumpeterian tradeoff revisited", American Economic Review, Vol. 72 No. 1, pp. 114-132.

Powell, W.W., Koput, K.W. and Smith-Doerr, L. (1996), "Interorganizational collaboration and the locus of innovation: Networks of learning in biotechnology", Administrative Science Quarterly, pp. 116-145.

Santamaría, L., Nieto, M.J. and Miles, I. (2012), "Service innovation in manufacturing firms: Evidence from Spain”, Technovation, Vol. 32 No. 2, pp. 144-155.

Sofka, W. and Grimpe, C. (2010), "Specialized search and innovation performance evidence across Europe", $R \& D$ Management, Vol. 40 No. 3, pp. 310-323.

Sundbo, J. (1997), "Management of innovation in services", The Service Industries Journal, Vol. 7 No. 3, pp. 432-55.

Tether, B.S. (2005), "Do services innovate (differently)? Insights from the European Innobarometer Survey", Industry \& Innovation, Vol. 12 No. 2, pp. 153-184.

Tether, B.S. and Tajar, A. (2008), "Beyond industry-university links: Sourcing knowledge for innovation from consultants, private research organisations and the public sciencebase", Research Policy, Vol. 37 No. 6, pp.1079-1095.

Utterback, J. and Abernathy, W. (1975), "A dynamic model of process and product innovation", Omega, Vol. 3 No. 6, pp. 639-656.

Vega-Jurado, J., Gutiérrez-Gracia, A., Fernández-de-Lucio, L. and Manjarres-Henríquez, I. (2008), "The effect of external and internal factors on firms' product innovation", Research Policy, Vol. 37 No. 4, pp. 616-632.

Vega-Jurado, J., Gutiérrez-Gracia, A. and Fernández-de-Lucio, I. (2009), "Does external knowledge sourcing matter for innovation? Evidence from the Spanish manufacturing industry", Industrial and Corporate Change, Vol. 18 No. 4, pp. 637-670.

Von Hippel, E. (1988), The sources of innovation. New York: Oxford University Press.

Von Hippel, E. (2005), Democratizing innovation. Cambridge, MA: MIT Press. 
Winter, S.G. (1984), "Schumpeterian competition in alternative technological regimes", Journal of Economic Behavior and Organization, Vol. 5 No. 3-4, pp. 287-320.

Zander, U. and Kogut, B. (1995), "Knowledge and the speed of the transfer and imitation of organizational capabilities: An empirical test", Organization Science, Vol. 6 No. 1, pp. 7692.

['] Non-core industries are marked with an asterisk in Table 1.

[ii ] On examining the distribution of these variables we saw, for instance, that in the case of SDEPTH, 65 per cent of the firms were in the categories 0 to 1 , for which SDEPTH and its square are the same value. 